\title{
PROFESSIONALISM
}

ISSN: 1893-1049

Volume 10 , No 1 (2020), e3326

https://doi.org/10.7577/pp.3326

\section{Positioning Each Other: A Metasynthesis of Pharmacist-Physician Collaboration}

\author{
Hilde Rakvaag, Gunn Elisabeth Søreide \& Reidun Lisbet \\ Skeide Kjome
}

University of Bergen, Norway

Contact: Hilde Rakvaag, University of Bergen, Norway, hilde.rakvaag@uib.no

\section{Abstract}

Interprofessional collaboration between different professions within health care is essential to optimize patient outcomes. Community pharmacists (CPS) and general practitioners (GPs) are two professions who are encouraged to increase their collaboration. In this metasynthesis we use a meta-ethnographic approach to examine the interpersonal aspects of this collaboration, as perceived by the professionals themselves. The metasynthesis firstly suggests that CPs and GPs have differing storylines about the cooperation between them. Secondly, CPs seem to position their profession in relation to the GPs, whereas GPs do not rely on the CPs to define their professional position. A successful collaboration between the two professions requires the CPs to reposition themselves through adopting a proactive approach towards the GPs. This proactive approach should comprise the delivery of specific clinical advice, as well as taking responsibility for this advice. In this way, they can build a more coinciding storyline of the joint agenda of improved patient care.

\section{Keywords}

Interprofessional collaboration, community pharmacists, general practitioners, meta-ethnography, positioning theory

(C) 2020 the authors. License: https://creativecommons.org/licenses/by/4.0/ (CC-BY 4.0) www.professionsandprofessionalism.com 


\section{Introduction}

Medication errors constitutes a substantial burden to patients, leading to unnecessary and avoidable illness and injury (World Health Organization (WHO), 2016). Medication errors also have great economic consequences, with an associated cost of nearly one percent of the total global health expenditure (WHO, 2017). The WHO states that one factor which may influence medication errors is poor communication between health care professionals (WHO, 2016), and advocates interprofessional education (IPE) and interprofessional collaborative practice, as this can improve patient safety and patient outcomes, and reduce health costs (WHO, 2010).

Already in 1998, a joint statement from the International Pharmaceutical Federation and the World Medical Association underscored the importance of the working relationship between pharmacists and physicians, and its consequences for patients, concluding that the patient will be best served when pharmacists and physicians collaborate (WHO, 1998). Collaboration between pharmacists and physicians in primary care is shown to improve patient outcomes and reduce health costs (Hwang, Gums \& Gums, 2017). Despite this, collaboration is limited. Research has identified a variety of factors influencing the collaboration between pharmacists and physicians (Bardet, Vo, Bedouch \& Allenet, 2015; Bollen, Harrison, Aslani \& Haastregt, 2018; Doucette, Nevins \& McDonough, 2005). However, there is no agreement on how to classify these factors, thus different classification systems and models exist (Bardet et al., 2015). One of the most widely used models is "The collaborative working relationship model" (CWR) (McDonough \& Doucette, 2001). In this model the influential factors are classified as individual characteristics, contextual characteristics and exchange characteristics. Exchange characteristics describes the personal interactions between pharmacists and physicians, and these elements are found to be especially important influential drivers of collaboration (Doucette et al., 2005; Zillich, McDonough, Carter \& Doucette, 2004). The importance of the exchange characteristics is supported by a meta-model by Bardet et al. (2015), which concludes that trust and interdependence are the two core elements of collaboration between pharmacists and physicians. While the importance of interpersonal factors is underscored in the abovementioned articles, these factors are rarely addressed exclusively and in depth.

Our aim is to address this limitation by exclusively exploring the interpersonal aspects of the collaboration between community pharmacists (CPs) ${ }^{1}$ and general practitioners (GPs) through performing a metasynthesis. The aim of a metasynthesis is to systematically interpret findings from previous qualitative research with the purpose of developing new explanations and fresh insights (Walsh \& Downe, 2005). In our metasynthesis, we will use positioning theory (Harré \& Langenhove, 1999b) as a theoretical framework to bring forward novel interpretations and insights. 


\section{Theoretical framework}

Positioning theory focuses on interpersonal interactions and the attribution of positions among interactants. It can be applied to understand the interactions between people both at an individual level and at a group level, were people serve as group representatives (Harré \& Langenhove, 1999a). The term "intergroup positioning" involves both the positioning of oneself or others at an individual level based upon group membership, and the positioning of oneself or others at a group level. To distinguish oneself and one's group from others, one uses linguistic devices such as "us" and "them", or specific group names (Tan \& Moghaddam, 1999), in our study CPs and GPs. A central element in positioning theory is the mutually determining triad consisting of speech acts, positions and storylines. A speech act is the act of making an utterance, and in our study the speech act is understood as the utterance about collaboration between CPs and GPs that the participants gave in the original research this metasynthesis draws on. A position comprises certain personal attributes, rights, duties and responsibilities, which are negotiable and the result of a dynamic relation between the participants in a social episode. A storyline is the conversational history according to which a social episode evolves and positions arise (Harré \& Langenhove, 1999b). When people participate in a social episode, they co-construct a storyline where each participant is given by others or claim for themselves, a position. Positioning can in other words be either interactive, which means that people position each other, or reflexive, which means that one positions oneself. In either case, positioning is not necessarily intentional (Davies \& Harré, 1999). In our metasynthesis, this theoretical framework offered a lens through which to study the CPs' and GPs' perceptions of their collaboration, with a focus on how they positioned themselves and one another.

\section{Method}

\section{Research design}

Metasyntheses can be done in different ways, and we chose to use the method of metaethnography (Noblit \& Hare, 1988) based on its systematic and stepwise procedure, consisting of seven steps (Box 1). To clarify the contents of each of the seven steps, we used the interpretations of Atkins et al. (2008).

\section{Box 1}

The seven steps of meta-ethnography (in bold) (Noblit \& Hare 1988) as applied in our study informed by the interpretations of Atkins et al. (2008). The steps are a description of the research process, yet they should not be seen as isolated steps or a linear process, but rather as an iterative process where some of the steps were performed simultaneously. 
1. Getting started: Determining a research question that could be informed by qualitative research.

2. Deciding what is relevant to the initial interest: Deciding which primary studies to include in the synthesis. This involves defining the focus of the synthesis (deciding how broad or narrow the scope of the synthesis should be), locating relevant studies (developing a search strategy, choosing databases and performing the search) and selecting studies for inclusion (deciding on inclusion -and exclusion criteria, screening and quality appraising the studies).

3. Reading the studies: Repeated reading of the studies to get as familiar as possible with the contents and details of the studies. Extracting emerging themes and concepts, as well as study characteristics, such as context, methods and type of participants.

4. Determining how the studies are related: Making a grid of key themes and concepts in each of the primary studies. Juxtaposing them and deciding how they are related. Making an initial assumption about the relationship between the studies regarding if they relate reciprocally (similar findings) or refutationally (conflicting findings) or both, and if they build a line of argument (explore different aspects that together can create a new interpretation).

5. Translating the studies into one another (in our study reciprocally): Comparing the themes and concepts in one primary study with the next, and the synthesis of these two studies with the next and so on.

6. Synthesizing translations: Creating a third-order interpretation/line-of-argument synthesis.

7. Expressing the synthesis: Reporting the outcomes of the synthesis in a form that is accessible to the intended audience, for example other researchers or health care professionals.

To ensure transparency, we reported our meta-ethnography in accordance with the recommendations in the eMERGe reporting guidance (France et al., 2019), to the extent that this guide was relevant to our exploratory study.

\section{Data collection}

Based on our study purpose, we made a search strategy with the aim of identifying qualitative studies about the collaboration between CPs and GPs which also elucidated interpersonal aspects of collaboration. Preparation of the search strategy, selection of bibliographic databases and the systematic database search was done in collaboration with an experienced academic librarian from within the medical field. We searched the electronic databases Embase, Medline, PsycInfo, ISI Web of Science and SweMed+, using the search strategy presented in Appendix 1. In addition, we performed citation snowballing and additional free searching using search words such as pharmacist, general practitioner and interprofessional collaboration. The outcome of our search is presented in Figure 1. 
Positioning Each Other

\section{Figure 1}

PRISMA Flow diagram (Moher, D., Liberati, A., Tetzlaff, J., Altman, D. G., \& The PRISMA group, 2009)
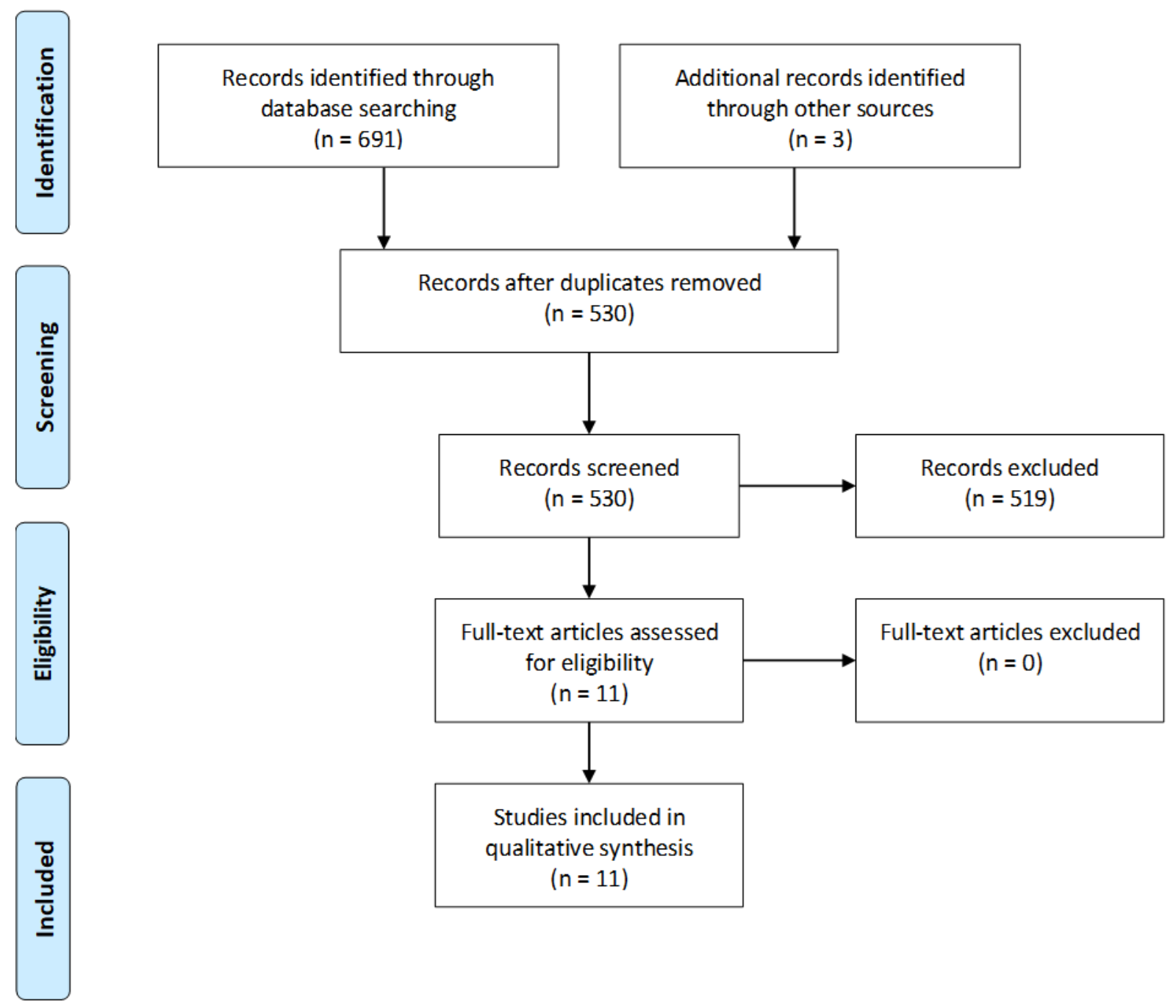

Our primary studies (Table 1) comprised empirical data from 397 individuals from seven countries. 
Positioning Each Other

Table 1

Characteristics of the included primary studies

\begin{tabular}{|c|c|c|c|c|}
\hline Study & Country & $\begin{array}{l}\text { Data } \\
\text { collection }\end{array}$ & Sample & Aim \\
\hline $\begin{array}{l}\text { Bradley, } \\
\text { Ashcroft \& } \\
\text { Noyce (2012) }\end{array}$ & England & $\begin{array}{l}\text { In-depth } \\
\text { semi- } \\
\text { structured } \\
\text { interviews }\end{array}$ & $\begin{array}{l}31 \mathrm{CPs} \\
27 \mathrm{GPs}\end{array}$ & $\begin{array}{l}\text { To present a new } \\
\text { model of } \\
\text { collaboration } \\
\text { derived from } \\
\text { interviews with GPs } \\
\text { and CPs involved in } \\
\text { service provision } \\
\text { that required some } \\
\text { form of } \\
\text { collaboration }\end{array}$ \\
\hline $\begin{array}{l}\text { Dey, } \\
\text { De Vries \& } \\
\text { Bosnic- } \\
\text { Anticevich } \\
\text { (2011) }\end{array}$ & Australia & $\begin{array}{l}\text { Semi- } \\
\text { structured } \\
\text { interviews }\end{array}$ & $\begin{array}{l}18 \mathrm{CPs} \\
7 \mathrm{GPs}\end{array}$ & $\begin{array}{l}\text { To gain deeper } \\
\text { understanding of the } \\
\text { expectations, } \\
\text { experiences and } \\
\text { perceptions of } \\
\text { Australian GPs and } \\
\text { CPs around } \\
\text { collaboration in } \\
\text { chronic illness } \\
\text { (asthma) } \\
\text { management in the } \\
\text { primary care setting }\end{array}$ \\
\hline $\begin{array}{l}\text { Gregory } \\
\& \text { Austin } \\
(2016)\end{array}$ & Canada & $\begin{array}{l}\text { Semi- } \\
\text { structured } \\
\text { telephone } \\
\text { interviews }\end{array}$ & $\begin{array}{l}11 \text { pharmacists } \\
8 \text { family } \\
\text { physicians }\end{array}$ & $\begin{array}{l}\text { To characterize the } \\
\text { cognitive model of } \\
\text { trust that exists } \\
\text { between } \\
\text { pharmacists and } \\
\text { family physicians } \\
\text { working in }\end{array}$ \\
\hline
\end{tabular}




\begin{tabular}{|c|c|c|c|c|}
\hline Study & Country & $\begin{array}{l}\text { Data } \\
\text { collection }\end{array}$ & Sample & Aim \\
\hline & & & & $\begin{array}{l}\text { collaborative } \\
\text { primary care settings }\end{array}$ \\
\hline $\begin{array}{l}\text { Löfler et al. } \\
\text { (2017) }\end{array}$ & Germany & $\begin{array}{l}\text { In-depth } \\
\text { narrative } \\
\text { interviews } \\
\text { and focus } \\
\text { groups }\end{array}$ & $\begin{array}{l}10 \mathrm{CPs} \\
15 \mathrm{GPs}\end{array}$ & $\begin{array}{l}\text { Investigating CP' } \\
\text { and GPs' views on } \\
\text { barriers to } \\
\text { interprofessional } \\
\text { collaboration in the } \\
\text { German health care } \\
\text { system }\end{array}$ \\
\hline $\begin{array}{l}\text { Paulino et al. } \\
\text { (2010) }\end{array}$ & Portugal & $\begin{array}{l}\text { Semi- } \\
\text { structured } \\
\text { interviews } \\
\text { and focus } \\
\text { groups }\end{array}$ & $\begin{array}{l}31 \mathrm{CPs} \\
6 \text { pharmacy } \\
\text { leaders } \\
2 \text { medical } \\
\text { leaders } \\
12 \text { physicians } \\
\text { (mix of GPs } \\
\text { and hospital } \\
\text { physicians) } \\
21 \text { patients }\end{array}$ & $\begin{array}{l}\text { To explore the } \\
\text { opinions and } \\
\text { experiences of a } \\
\text { range of } \\
\text { stakeholders on } \\
\text { interprofessional } \\
\text { working } \\
\text { relationships } \\
\text { between CPs and } \\
\text { physicians }\end{array}$ \\
\hline $\begin{array}{l}\text { Rathbone, } \\
\text { Mansoor, } \\
\text { Krass, } \\
\text { Hamrosi \& } \\
\text { Aslani (2016) }\end{array}$ & Australia & $\begin{array}{l}\text { Focus } \\
\text { groups }\end{array}$ & $\begin{array}{l}23 \mathrm{CPs} \\
22 \mathrm{GPs}\end{array}$ & $\begin{array}{l}\text { To propose a model } \\
\text { of interprofessional } \\
\text { collaboration } \\
\text { between CPs and } \\
\text { GPs within the } \\
\text { context of } \\
\text { identifying and } \\
\text { improving } \\
\text { medication non- }\end{array}$ \\
\hline
\end{tabular}


Positioning Each Other

\begin{tabular}{|c|c|c|c|c|}
\hline Study & Country & $\begin{array}{l}\text { Data } \\
\text { collection }\end{array}$ & Sample & Aim \\
\hline & & & & $\begin{array}{l}\text { adherence in } \\
\text { primary care }\end{array}$ \\
\hline Rieck (2014) & Australia & $\begin{array}{l}\text { Semi- } \\
\text { structured } \\
\text { interviews }\end{array}$ & $\begin{array}{l}22 \mathrm{CPs} \\
22 \mathrm{GPs}\end{array}$ & $\begin{array}{l}\text { To explore the } \\
\text { perceptions and } \\
\text { attitudes of CPs and } \\
\text { GPs regarding the } \\
\text { CP-GP relationship } \\
\text { and its impact on CP- } \\
\text { GP collaboration in } \\
\text { chronic disease } \\
\text { management in } \\
\text { primary healthcare }\end{array}$ \\
\hline $\begin{array}{l}\text { Rubio-Valera } \\
\text { et al. (2012) }\end{array}$ & Spain & $\begin{array}{l}\text { Semi- } \\
\text { structured } \\
\text { interviews }\end{array}$ & $\begin{array}{l}19 \mathrm{CPs} \\
18 \mathrm{GPs}\end{array}$ & $\begin{array}{l}\text { To identify and } \\
\text { analyze factors } \\
\text { affecting GP-CP } \\
\text { collaboration }\end{array}$ \\
\hline $\begin{array}{l}\text { Snyder et al. } \\
(2010)\end{array}$ & USA & $\begin{array}{l}\text { Semi- } \\
\text { structured } \\
\text { interviews }\end{array}$ & $\begin{array}{l}5 \text { CPs } \\
5 \text { physicians }\end{array}$ & $\begin{array}{l}\text { To describe the } \\
\text { professional } \\
\text { exchanges that } \\
\text { occurred between } \\
\text { CPs and physicians } \\
\text { engaged in } \\
\text { successful } \\
\text { collaborative } \\
\text { working } \\
\text { relationships }\end{array}$ \\
\hline
\end{tabular}




\begin{tabular}{|c|c|c|c|c|}
\hline Study & Country & $\begin{array}{l}\text { Data } \\
\text { collection }\end{array}$ & Sample & Aim \\
\hline $\begin{array}{l}\text { Van, Mitchell } \\
\& \text { Krass } \\
(2011)\end{array}$ & Australia & $\begin{array}{l}\text { Semi- } \\
\text { structured } \\
\text { interviews, } \\
\text { face-to-face } \\
\text { and } \\
\text { telephone }\end{array}$ & $\begin{array}{l}15 \mathrm{CPS} \\
15 \mathrm{GPS}\end{array}$ & $\begin{array}{l}\text { To investigate the } \\
\text { nature and extent of } \\
\text { interactions } \\
\text { between GPs and } \\
\text { CPs and the factors } \\
\text { that influence these } \\
\text { interactions in the } \\
\text { context of } \\
\text { professional } \\
\text { pharmacy services }\end{array}$ \\
\hline $\begin{array}{l}\text { Weissenborn, } \\
\text { Haefeli, } \\
\text { Peters-Klimm } \\
\text { \& Seidling } \\
\text { (2017) }\end{array}$ & Germany & $\begin{array}{l}\text { In-depth } \\
\text { semi- } \\
\text { structured } \\
\text { interviews } \\
\text { and focus } \\
\text { groups }\end{array}$ & $\begin{array}{l}19 \mathrm{CPs} \\
13 \mathrm{GPs}\end{array}$ & $\begin{array}{l}\text { To assess CPs' and } \\
\text { GPs' perceptions of } \\
\text { interprofessional } \\
\text { communication with } \\
\text { regard to content } \\
\text { and methods of } \\
\text { communication as a } \\
\text { basis to } \\
\text { subsequently } \\
\text { develop best- } \\
\text { practice } \\
\text { recommendations } \\
\text { for information } \\
\text { exchange }\end{array}$ \\
\hline
\end{tabular}

$\mathrm{CP}$ : community pharmacist, GP: general practitioner

Searching for qualitative studies can be challenging since qualitative research is not always indexed correctly in electronic databases, and the terms used in the titles are sometimes not a direct reflection of the topic (Evans, 2002). Despite our attempt to identify all relevant studies, we are aware of the possibility that additional studies suitable for inclusion in our synthesis may exist. However, the selection of studies was sufficient for our purposes, as it has provided an overview of significant research in the field. Also, while including more 
studies into our synthesis might add additional findings, a large number of included studies is not a goal in itself in metasyntheses, as one can easily lose track and end up with a superficial analysis (Campbell et al., 2011).

The first and last author screened all titles and abstracts independently, and potentially relevant articles were discussed, read in full text and appraised according to the following inclusion criteria: empirical qualitative studies, written in English or a Scandinavian language, published between 2010 and 2017, about collaboration between community pharmacists and physicians in primary care, and containing findings regarding interpersonal aspects of collaboration. Studies concerning pharmacists integrated in a primary health care team or located in a physician's practice were excluded. This due to the likelihood of these settings influencing the interpersonal relationships in different ways than the typical primary care setting, where CPs and GPs most often work physically isolated from each other. The eleven studies which met our inclusion criteria were quality appraised by the first and last author, using the Critical Appraisal Skills Programme (CASP) checklist (2017) for qualitative research.

\section{Data analysis and synthesis}

The primary studies were read thoroughly and independently in full text by the first and last author to get an overview and identify key themes and concepts in each study as well as study characteristics such as context, types of participants and study design. Data was extracted by the first author in collaboration with the last author. Only findings regarding interpersonal aspects of collaboration were extracted, while findings regarding factors such as practice setting, infrastructure, systems of reimbursement, data sharing, time constraints and practitioner demographics were excluded, as these factors were outside of our scope. We made the decision to extract findings only from the results section of the articles. This choice was discussed thoroughly in advance, and decided upon due to the fact that the discussion section often contains information based upon other sources than the study findings, for example research done by others, and authors' personal opinions. We attempted to only extract concepts developed by authors of the primary studies, but participant quotes may also have been extracted due to a low level of interpretation in many of the primary studies, and hence difficulties in distinguishing participant quotes from author interpretations. An exception is the participants quotes that are presented in our results section, these were selected deliberately to serve as illustrations to our findings. The further analysis of the studies will be described in the following and is illustrated in Appendix 2.

Inspired by Atkins et al. (2008), we first used thematic analysis to identify thematic categories and organize the key themes and concepts in each study into these categories. 
During this step of the analysis, we tried to preserve the terminology used by the original authors. To get an overview across all studies and to determine how the studies were related, we structured the eleven studies and the identified 13 thematic categories into a grid. Appendix 3 shows an excerpt from the grid for one of the thematic categories, labeled "shopkeepers".

Data within the different categories then formed the basis for the translation of the primary studies into one another. We found that the focus and themes of the included primary studies were sufficiently similar for a reciprocal translation ${ }^{2}$ to be made. The original categories were revised and reconfigured as the analysis progressed through discussions on how they were related; some were merged, some were split up and new categories and subcategories were agreed upon. The concepts of the different primary studies were compared by translating the data within each category from one study into the next, and then translating this synthesis into the next study and so on, while at the same time keeping our minds open for emerging new categories. We also attempted to examine if different contexts, such as country, had an influence on the findings. Our translations were finally synthesized into three main categories.

Based on our translations, we then created our third order interpretations by applying positioning theory to identify different positions that the CPs and GPs assigned to themselves and each other through reflexive and interactive positioning. These positions further served as a basis to identify the CPs' and GPs' main storylines. Throughout the analytical process, findings and categories were discussed with the second author. The outcome of this metasynthesis is presented as a line-of-argument synthesis in the form of storylines in the results section, and further elaborated on through the framework of positioning theory in the discussion section.

\section{Results}

We found coherence across the different countries in the way pharmacists and physicians perceived their challenges related to collaboration. All of the studies used individual interviews or focus groups or a combination of these, and included both pharmacists and physicians, with a small predominance of pharmacists. One study also included pharmacy and medical leaders and patients. The studies varied regarding the level of collaboration that existed between the participating pharmacists and physicians. Some were involved in a highly collaborative working relationship, but the majority were not.

There were two sets of stories that asserted themselves in the results of the primary studies included in our synthesis: stories about limited collaboration and stories about successful collaboration. In the following, we will present the dominant storylines and positions in these two sets of stories. 


\section{The stories of limited collaboration}

Most of the CP and GP participants described the collaboration between the two professions as limited. However, the two professions described the lack of collaboration using different storylines. Within their respective storylines, the CPs and GPs also took on different positions, and positioned the other profession in different ways.

\section{The CPs' storyline}

This storyline was concerned with a desire to deliver improved patient care through engaging in interprofessional collaboration with the GPs, while experiencing the GPs as not very forthcoming. Most of the CPs in the included primary studies seemed to hold the opinion that both the GPs, the patients and they themselves would benefit from an interprofessional collaboration (Dey, de Vries \& Bosnic-Anticevich, 2011; Paulino et al., 2010). However, there were many accounts of them feeling disrespected, underappreciated and underevaluated by the GPs (Dey et al., 2011; Gregory \& Austin, 2016; Löffler et al., 2017; Paulino et al., 2010; Rieck, 2014; Snyder et al., 2010; Van, Mitchell \& Krass, 2011; Weissenborn, Haefeli, Peters-Klimm \& Seidling, 2017):

I trust them to do their job-it's frustrating, okay, sometimes it feels almost like patronizing? - when you know they don't trust your recommendation just because they think, well, you're [air quotes] "just a pharmacist". (CP) (Gregory \& Austin, 2016, p. 241)

Some CPs specified that they had knowledge that was additional and complementary to that of the GPs (Gregory \& Austin, 2016; Paulino et al., 2010; Snyder et al., 2010). They generally positioned themselves as clinically competent to contribute in patient care by solving drug related problems (Bradley, Ashcroft \& Noyce, 2012; Gregory \& Austin, 2016; Löffler et al., 2017; Paulino et al., 2010; Snyder et al., 2010), and wished for stronger support from the GPs (Bradley et al., 2012; Dey et al., 2011; Gregory \& Austin, 2016; Löffler et al., 2017; Weissenborn et al., 2017). Yet, they ultimately positioned the GPs as the ones responsible for the patients' outcome, and seemed reluctant to take on this level of responsibility themselves (Bradley et al., 2012; Paulino et al., 2010):

I'd rather not have the responsibility on my head... I'd like [the GPs] to be the ones who explain, initiate the whole service, and I can just be there as an addition... (CP) (Bradley et al., 2012, p. 43)

The CPs positioned themselves as dependent on the GPs to be able to contribute, and hereby placed themselves in the position as the "noble" profession who were looking to improve the treatment of patients through interprofessional collaboration, while being rejected by the GPs (Snyder et al., 2010). Nevertheless, there was one account of CPs 
positioning themselves as passive, recognizing that they were also partly to blame for the limited collaboration with the GPs (Paulino et al., 2010).

The CPs generally positioned the GPs as highly competent, respected and trustworthy (Gregory \& Austin, 2016; Rieck, 2014):

Well, of course, why wouldn't you trust them? They're doctors, right, so they've proven themselves already. (CP) (Gregory \& Austin, 2016, p. 240)

Gregory and Austin (2016) point out that the GPs do not need to earn the CPs' trust; it is conferred on them implicitly through their status and title as GPs. This implicit trust was also evident in three of the other primary articles (Bradley et al., 2012; Snyder et al., 2010; Van et al., 2011), and also shone through a large proportion of the material, where the focus was on what could improve the GPs' opinions about the CPs, and not the other way around (Rathbone, Mansoor, Krass, Hamrosi \& Aslani, 2016; Rieck, 2014; Rubio-Valera et al., 2012). Nevertheless, the GPs were not only featured in positive terms. They were also positioned by the CPs as territorial and as a profession with a "bad attitude" who do not want to engage in interprofessional collaboration for the best of patients (Dey et al., 2011; Gregory \& Austin, 2016; Löffler et al., 2017; Paulino et al., 2010; Rieck, 2014; Snyder et al., 2010):

You can't tell a doctor anything, he can't learn from anybody, he's supposed to know it all... (CP) (Dey et al., 2011, p. 25)

Some CPs positioned the GPs as having a monopoly on the patient, and were conscious of not impeaching on their professional territory. There was a perception among several CPS that the GPs sometimes perceived what was intended as helpful requests or advice from the CPs' side as criticism, and the CPs therefore tried not to step on the GPs' toes (Dey et al., 2011; Löffler et al., 2017; Paulino et al., 2010; Weissenborn et al., 2017). Some CPs lacked the confidence to confer their clinical opinions. Previous negative response from the GPS could result in the CPs avoiding contacting the GP to make an intervention, although they considered the intervention important (Dey et al., 2011; Löffler et al., 2017; Paulino et al., 2010):

Sometimes we actually fear calling there, because we are scared of being snapped at. You know, we've sometimes had such bad experiences... (CP) (Löffler et al., 2017, p. 3)

\section{The GPs' storyline}

We found the main GPs' storyline to be that they delivered good enough patient care on their own. The included primary articles presented several accounts of the GPs showing 
limited interest and awareness of the CPs' competencies and possible contributions to a collaboration (Dey et al., 2011; Löffler et al., 2017; Paulino et al., 2010; Rieck, 2014):

(...) I dare say that the majority of physicians doesn't have the slightest idea of what pharmaceutical care is. (Physician) (Paulino et al., 2010, p. 597)

Some GPs presented a negative attitude towards CPs who were calling them on the phone with what they perceived as unnecessary inquiries, and it was underlined that CPs were of little help when calling to point out mistakes without offering a specific proposal for a solution (Löffler et al., 2017). The GPs seemed to hold the opinion that the CPs would be the ones with most to gain from a collaboration, while they themselves and the patients would have less to gain (Dey et al., 2011; Paulino et al., 2010; Snyder et al., 2010), hence they were less motivated to collaborate. Some perceived the CPs to be useful collaborators in the way that they could perform less important tasks to free the GPs' time (Bradley et al., 2012; Paulino et al., 2010):

I would much prefer that I spent my time dealing with complex stuff than spend my day doing unnecessary things that somebody else can do. (GP) (Bradley et al., 2012, p. 43)

The GPs generally positioned themselves as more competent than the CPs (Bradley et al., 2012; Dey et al., 2011; Gregory \& Austin, 2016; Löffler et al., 2017; Paulino et al., 2010; Rieck, 2014; Rubio-Valera et al., 2012; Weissenborn et al., 2017). In agreement with the CPs, the GPs also positioned themselves as the ones with the most responsibility (Dey et al., 2011; Gregory \& Austin, 2016; Löffler et al., 2017; Snyder et al., 2010).

Some GPs defined their limited relationship with the CPs as a good one, seemingly not perceiving their limited collaboration as a problem in the same way that the CPs did (Dey et al., 2011; Löffler et al., 2017). At the same time, some positioned the CPs as encroachers into the GPs' domain (Bradley et al., 2012; Löffler et al., 2017; Paulino et al., 2010):

Pharmacists aren't doctors. I think every monkey should stay on his own branch. (Physician) (Paulino et al., 2010, p. 599)

In relation to this, the CPs were positioned by the GPs as unreliable and incompetent until the opposite had been proven. For the CPs to gain the GPs' trust, they had to gradually earn it over time through being proactive and proving their clinical skills in a way that had a positive impact on patients' outcomes (Gregory \& Austin, 2016; Snyder et al., 2010; Van et al., 2011): 
You just know, after a while. You can tell if they're competent, committed, someone you want to rely on. You have to see them in action. (Family physician) (Gregory \& Austin, 2016, p. 239)

The GPs' positioning of CPs as "shopkeepers" or businesspeople was found in several of the included articles (Bradley et al., 2012; Löffler et al., 2017; Paulino et al., 2010; Rieck, 2014; Rubio-Valera et al., 2012; Van et al., 2011). This position had two aspects: the first was that the GPs mistrusted the CPs' agenda because of the commercial aspect of community pharmacy. The CPs were seen as businesspeople, and the GPs were therefore uncertain about whether the CPs' agenda was patients' benefit or their own economic benefit (Bradley et al., 2012; Löffler et al., 2017; Paulino et al., 2010; Rubio-Valera et al., 2012; Van et al., 2011). The other aspect was the GPs' lack of trust and confidence in CPs' clinical abilities (Bradley et al., 2012; Gregory \& Austin, 2016; Löffler et al., 2017; Paulino et al., 2010; Rieck, 2014; Weissenborn et al., 2017). This could be based both on previous bad experiences with individual CPs (Gregory \& Austin, 2016), and on prejudice towards the profession as a whole, with the GPs viewing the CPs as "merely shopkeepers" with low clinical competence (Paulino et al., 2010; Rieck, 2014; Van et al., 2011). Because the CPs do not make their profit from the delivery of clinical services, but rather from the products they sell, they were not regarded as being part of the healthcare system on an equal level as other healthcare personnel (Rieck, 2014):

Well, most of the allied health professionals, physios... I don't know that much about how they actually work, but my understanding is that most of the money is made from their professional advice. So, it's actually themselves and the quality of their advice they give, they make money for. Where pharmacists are different, they make their money from what they actually sell. (GP) (Rieck, 2014, p. 442-443)

\section{The stories of successful collaboration}

Some CPs and GPs described various degrees of successful collaboration. In these stories the two groups of professionals had a more coinciding storyline which was about a mutual interest in collaborating and a shared motivation in improved patient care, while they still held different positions:

... we both have different jobs but we both have an end goal and that is to take care of the patient ... (Physician) (Snyder et al., 2010, p. 316)

I think it's easier working with some doctors because we share the same belief in what we're here for... we're both part of the total solution for patients... we're meant to work together. (CP) (Van et al., 2011, p. 369) 
Both CPs and GPs acknowledged a "personal relationship" or "knowing each other", preferably through face-to-face interactions, as important for successful collaboration (Bradley et al., 2012; Dey et al., 2011; Gregory \& Austin, 2016; Löffler et al., 2017; Paulino et al., 2010; Rathbone et al., 2016; Rieck, 2014; Rubio-Valera et al., 2012; Snyder et al., 2010; Van et al., 2011; Weissenborn et al., 2017). Many participants from both professions perceived this as being essential primarily in that it made the GPs aware of the CPs' competencies, services and possible contributions (Bradley et al., 2012; Paulino et al., 2010; Rieck, 2014; Snyder et al., 2010). But it was also highlighted as an opportunity for the two professions to align role perceptions, clinical goals and perspectives (Paulino et al., 2010; Rathbone et al., 2016; Rubio-Valera et al., 2012; Van et al., 2011; Weissenborn et al., 2017). This could help reduce stigmatized views towards the other professional in both directions (Paulino et al., 2010; Rubio-Valera et al., 2012). In this, both the GPs and the CPs themselves positioned the CPs as the proactive part. This in the sense that the CPs primarily were the ones who had to take the initiative to establish a personal relationship, prove their clinical competence, make their possible contribution to a collaboration familiar, and initiate and maintain a collaboration with the GPs. This proactive approach by the CPs was described in several of the included studies as being important to foster a successful collaboration (Paulino et al., 2010; Rieck, 2014; Snyder et al., 2010; Van et al., 2011):

... the pharmacist has to play an active role, because the novelty comes from him, not from the physician. (CP) (Paulino et al., 2010, p. 600)

When the GPs had gotten to know the CPs, they more often positioned them as trustworthy, clinically competent, helpful and supportive (Bradley et al., 2012; Gregory \& Austin, 2016; Rieck, 2014):

If the right patient gets to the right person, they do a better job perhaps than the doctors... more thorough for certain things ... certainly advice regarding drug interactions, it could be argued that the pharmacist does that better ... we're all fairly modern in our approach, we can live with it. (GP) (Bradley et al., 2012, p. 43)

Nevertheless, this did not necessarily apply to the profession in general, but could be limited to the individual CPs whom they had an interpersonal relationship with (Paulino et al., 2010).

\section{Discussion}

Differences in organization within the primary care systems of the seven countries included in our metasynthesis could potentially be problematic in terms of transferability (Malterud, 2001), but despite large geographical distances, the systems in which the pharmacists and physicians worked were found similar enough for the studies to be synthesized. We found 
coherence across the countries in the way pharmacists and physicians perceived their challenges related to collaboration, something that strengthens the transferability of our findings. Our use of the eMERGe reporting guidance (France et al., 2019) should increase transparency, and the use of CASP (Critical Appraisal Skills Programme, 2017) should ensure that the included studies are of acceptable quality. A limitation of the included studies was that they were generally more descriptive than interpretative. Yet, they served the purpose of our study, and the use of positioning theory (Harré \& Langenhove, 1999b) made it possible for us to extend the level of interpretations to present what we perceive as new insights. This theoretical framework has influenced our results by affecting which findings we have placed emphasis on. Using other relevant theoretical frameworks, such as sociological theories of the professions (Traulsen \& Bissel, 2004), most likely would have led to different findings, as a result of a different focus. Nevertheless, positioning theory was chosen after a thorough discussion of different possible theories, as this approach allowed us to go into a dialogue with our data and identify how GPs and CPs described and positioned their professions in general, as well as in relation to each other.

The first and last authors are both pharmacists, and this influenced how findings were understood and interpreted. These two authors could for instance easily recognise and identify with the CPs' description and positioning of their profession as well as the way the relationship between CPs and GPs was described. Their knowledge of the pharmaceutical profession as well as international research on this profession, ensured the interpretations of the CPs' positions and storylines were relevant and reasonable. Although originally trained as a pharmacist, the last author received her research training in a research group consisting of primarily GPs. Her academic knowledge of GPs' training and work, enabled us to make relevant and reasonable interpretations also of the GPs' positions and storylines. The second author, who is a highly competent qualitative researcher from the field of pedagogy, had no insider experience or knowledge, neither of the medical nor of the pharmaceutical profession. To avoid that interpretations developed into more biased opinions, the second author therefore used her "outsider" position continuously in the discussions about the findings and how these best could be interpreted and communicated. In these interdisciplinary discussions, preconceptions were discussed openly. Preliminary findings were also presented and discussed at national and international research conferences. Together, these measures ensured reflexivity (Malterud, 2001) as well as a nuanced perspective in our metasynthesis.

We found that the CPs tended to interpret their own position as a profession in relation to the profession of the GPs, whereas the GPs did not seem to rely on the CPs to define their position. The GPs were generally not concerned with how the CPs perceived them, whereas the CPs emphasized the GPs' perceptions about them and about their rights and duties as a 
profession. The CPs were positioned both through interactive and reflexive positioning as somewhat dependent on the GPs' approval to be allowed to have a clinical opinion. There seemed to be an overall acceptance by the CPs of this position, instead of them trying to renegotiate their position to a more autonomous one. Other authors have touched upon similar findings, for example Svensberg, Kälvemark Sporrong, Håkonsen \& Toverud (2015, p. 261) found that: "Some pharmacists questioned their place in patient care, based on doctors' attitudes". In an exploratory study about the lack of responsibility and confidence among pharmacists, it was mentioned that the hierarchical structure of the medical system made some pharmacists feel that: "asking permission" was necessary to be able to make clinical decisions (Frankel \& Austin, 2013, p. 157), and Rosenthal, Austin \& Tsuyuki (2010, p. 39) states that: "Pharmacists seem to be overly concerned with the perception that other health care workers and other professions have of them". Notions about a hierarchical structure of the medical system and a territorial behavior of the GPs were also found in our metasynthesis. The CPs were found to promote what they saw as their unique and complimenting competencies, while the GPs were found to highlight their superiority over the CPs. This strategy was similarly observed in a study by Lee, Lessem \& Moghaddam (2008), with participants competing for internships. Lower-status participants were seen to focus on their unique qualities instead of directly comparing themselves to the others, whereas higher-status participants directly compared themselves with a focus on being "better". The strategy of the CPs, focusing on their complimenting skills, may be born from a wish to maintain inter-group harmony (Harré, Moghaddam, Cairnie, Rothbart \& Sabat, 2009). By not positioning one's group as being in competition with another group, but rather differentiating oneself from the others through the search for vacant spaces, one can avoid conflict (Harré et al., 2009). The GPs, being a higher-status group compared to the CPs, did not seem to have the same fear of inter-group conflict.

The CPs were found to position themselves as not having the right or duty to take responsibility for the patients' outcomes. There may be several reasons for this, such as their perception that the GPs are the ones responsible for the patients and, as mentioned above, the CPs' wish to avoid conflict with the GPs. Another aspect is that they may lack the confidence, which for some CPs could be legitimate due to an actual lack of clinical competence, while it for others could be due to an underestimation of their own skills in combination with a great respect for the GPs and their opinions. However, we found that the GPs only trust CPs on the basis of regular clinical recommendations that improves patients' outcomes. This finding implies that the CPs' defensive demeanor, perhaps based on their perceived lack of responsibility, could bring them into a negative circle by contributing to the GPs' mistrust in them. This is in line with conclusions from Blöndal, Jonsson, Kälvemark Sporrong \& Almarsdóttir (2017). In their study they interviewed 20 GPs on Iceland, and found that to improve communication between GPs and CPs, the CPs need 
to demonstrate their potential, use their expertise and dare to take responsibility for patient care.

In the stories about the CPs and GPs involved in good working relationships, there was not a lot of focus on the GPs' positions. In addition to the importance of knowing each other personally and having aligned perspectives and goals, the main focus was on the changed positions of the CPs from passive to active, unfamiliar to familiar, questionable to trustworthy, incompetent to competent, encroaching to supportive and subordinate to equitable. The most important change in the position of the GPs was that they moved from being unaware to being aware of the CPs' competencies and possible contributions to a collaboration. This suggests that the CPs are the ones who have to make the changes in order to enhance the collaboration with the GPs.

\section{Renegotiating new positions-introducing new storylines}

The acceptance or rejection of prevailing storylines determines whether a relation between two groups with different power remains stable or changes. Storylines and positions are not written in stone and can be altered through the introduction of new positions and storylines. Thus, group positions can be renegotiated, and a subordinate group can introduce new storylines for itself, thereby creating social changes in the established intergroup relation. In this way, group positions that used to stand in opposition to each other ("us vs them") can be realigned into complementary positions ("we must work together") (Tan \& Moghaddam, 1999). One way of introducing such new storylines could be through IPE, where students from different professions within health care, among them medical and pharmacy students, come together to learn with, from and about each other with the goal of facilitating effective future collaboration and hence improved quality of care (Bondevik, Holst, Haugland, Baerheim \& Raaheim, 2015). IPE is currently promoted as the way forward to increase interprofessional collaboration within health care on a global level (WHO, 2010; Frenk et al., 2010).

The dominant storyline among the CPs and GPs involved in successful collaboration was found to be that they had a shared motivation and a common goal: improved patient care. The CPs who were not involved in successful collaboration also held the view that a collaboration with the GPs would benefit the patients, whereas the GPs not involved in successful collaboration had doubts about the possible patient benefits. These GPs were unsure of the CPs' skills and motives based on the perception of them as shopkeepers. If the CPs could manage to change this storyline to one about them both working for the best of patients, this would increase the probability of a successful collaboration between them. However, to be able to do this, the CPs must first change their own storyline about themselves. The CPs should try to replace the old storyline about their group being less 
responsible with a new storyline, where they use their unique competencies to improve patient care by making clear recommendations, have the confidence to stand up for these recommendations, and thus also share responsibility with the GPs for the outcomes, positive or negative. When the GPs experience the CPs making clear recommendations that improve patient outcomes, our findings suggest that their trust in the CPs increases. This would be an important step in the right direction towards working for a better collaboration and the common goal of improved patient care.

\section{Acknowledgments}

The authors wish to thank Regina Küfner Lein, academic librarian at Bergen University Library, for her support in the literature search.

\section{Article history}

Received: 01 Apr 2019

Accepted: 04 Feb 2020

Published: 20 May 2020

\section{References}

Atkins, S., Lewin, S., Smith, H., Engel, M., Fretheim, A., \& Volmink, J. (2008). Conducting a meta-ethnography of qualitative literature: Lessons learnt. BMC Medical Research Methodology, 8(21). https://doi.org/10.1186/1471-2288-8-21

Bardet, J. D., Vo, T. H., Bedouch, P., \& Allenet, B. (2015). Physicians and community pharmacists collaboration in primary care: A review of specific models. Research in Social and Administrative Pharmacy, 11(5), 602-622. https://doi.org/10.1016/j.sapharm.2014.12.003

Blöndal, A. B., Jonsson, J. S., Sporrong, S. K., \& Almarsdóttir, A. B. (2017). General practitioners' perceptions of the current status and pharmacists' contribution to primary care in Iceland. International Journal of Clinical Pharmacy, 39, 945-952. https://doi.org/10.1007/s11096-017-0478-7

Bollen, A., Harrison, R., Aslani, P., \& Haastregt, J. C. M. v. (2018). Factors influencing interprofessional collaboration between community pharmacists and general practitioners - A systematic review. Health \& Social Care in the Community, 27(4). https://doi.org/10.1111/hsc.12705

Bondevik, G. T., Holst, L., Haugland, M., Baerheim, A., \& Raaheim, A. (2015). Interprofessional workplace learning in primary care: Students from different health professions work in teams in real-life settings. International Journal of Teaching and Learning in Higher Education, 27(2), 175-182. www.isetl.org/ijtlhe/pdf//JTLHE1954.pdf 
Bradley, F., Ashcroft, D. M., \& Noyce, P. R. (2012). Integration and differentiation: A conceptual model of general practitioner and community pharmacist collaboration. Research in Social and Administrative Pharmacy, 8(1), 36-46. https://doi.org/10.1016/j.sapharm.2010.12.005

Campbell, R., Pound, P., Morgan, M., Daker-White, G., Britten, N., Pill, R., . . Donovan, J. (2011). Evaluating meta-ethnography: Systematic analysis and synthesis of qualitative research. Health Technology Assessment, 15(43). https://doi.org/10.3310/hta15430

Critical Appraisal Skills Programme. (2017). CASP qualitative checklist. Retrieved from http://media.wix.com/ugd/dded87 25658615020e427da194a325e7773d42.pdf

Davies, B., \& Harré, R. (1999). Positioning and personhood. In R. Harré, \& L. van Langenhove (Eds.), Positioning theory: Moral contexts of intentional action (pp. 32-52). Oxford: Blackwell.

Dey, R. M., de Vries, M. J. W., \& Bosnic-Anticevich, S. (2011). Collaboration in chronic care: Unpacking the relationship of pharmacists and general medical practitioners in primary care. International Journal of Pharmacy Practice, 19(1), 21-29. https://doi.org/10.1111/j.2042-7174.2010.00070.x

Doucette, W. R., Nevins, J., \& McDonough, R. P. (2005). Factors affecting collaborative care between pharmacists and physicians. Research in Social and Administrative Pharmacy, 1(4), 565-578. https://doi.org/10.1016/j.sapharm.2005.09.005

Evans, D. (2002). Database searches for qualitative research. Journal of the Medical Library Association, 90(3), 290-293. https://www.ncbi.nlm.nih.gov/pmc/articles/PMC116400/pdf/i0025-7338-090-03-0290.pdf

France, E. F., Cunningham, M., Ring, N., Uny, I., Duncan, E. A., Jepson, R. G., . . Noyes, J. (2019). Improving reporting of meta-ethnography: The eMERGe reporting guidance. Journal of Advanced Nursing, 75(5), 1126-1139. https://doi.org/10.1111/jan.13809

Frankel, G. E., \& Austin, Z. (2013). Responsibility and confidence: Identifying barriers to advanced pharmacy practice. Canadian Pharmacists Journal, 146(3), 155-161. https://doi.org/10.1177/1715163513487309

Frenk, J., Chen, L., Bhutta, Z. A., Cohen, J., Crisp, N., Evans, T., . . Zurayk, H. (2010). Health professionals for a new century: Transforming education to strengthen health systems in an interdependent world. The Lancet, 376(9756), 1923-1958. https://doi.org/10.1016/S0140-6736(10)61854-5

Gregory, P. A., \& Austin, Z. (2016). Trust in interprofessional collaboration: Perspectives of pharmacists and physicians. Canadian Pharmacists Journal, 149(4), 236-245. https://doi.org/10.1177/1715163516647749

Harré, R., \& van Langenhove, L. (1999a). The Dynamics of Social Episodes. In R. Harré, \& L. van Langenhove (Eds.), Positioning theory: Moral contexts of intentional action (pp. 1-13). Oxford: Blackwell. 
Harré, R., \& van Langenhove, L. (1999b). Introducing Positioning Theory. In R. Harré, \& L. van Langenhove (Eds.), Positioning theory: Moral contexts of intentional action (pp. 1431). Oxford: Blackwell.

Harré, R., Moghaddam, F. M., Cairnie, T. P., Rothbart, D., \& Sabat, S. R. (2009). Recent advances in positioning theory. Theory \& Psychology, 19(1), 5-31. https://doi.org/10.1177/0959354308101417

Hwang, A. Y., Gums, T. H., \& Gums, J. G. (2017). The benefits of physician-pharmacist collaboration. The Journal of Family Practice, 66(12), E1-E8.

Lee, N., Lessem, E., \& Moghaddam, F. M. (2008). Standing out and blending in: Differentiation and conflict. In Global conflict resolution through positioning analysis (pp. 113-131). New York: Springer. https://doi.org/10.1007/978-0-387-72112-5 7

Löffler, C., Koudmani, C., Bohmer, F., Paschka, S. D., Hock, J., Drewelow, E., . . A Altiner, A. (2017). Perceptions of interprofessional collaboration of general practitioners and community pharmacists - a qualitative study. BMC Health Services Research, 17. https://doi.org/10.1186/s12913-017-2157-8

Malterud, K. (2001). Qualitative research: Standards, challenges, and guidelines. The Lancet, 358(9280), 483-488. https://doi.org/10.1016/S0140-6736(01)05627-6

McDonough, R. P., \& Doucette, W. R. (2001). Dynamics of Pharmaceutical Care. Journal of the American Pharmacists Association, 41(5), 682-692. https://doi.org/10.1016/S10865802(16)31315-8

Moher, D., Liberati, A., Tetzlaff, J., Altman, D. G., \& The PRISMA group (2009). Preferred reporting items for systematic reviews and meta-analyses: The PRISMA statement. PLoS Medicine 6(7). https://doi.org/10.1371/journal.pmed.1000097

Noblit, G. W., \& Hare, R. D. (1988). Meta-ethnography: Synthesizing Qualitative Studies. Newbury Park, Calif: SAGE Publications. https://doi.org/10.4135/9781412985000

Paulino, E., Guerreiro, M. P., Cantrill, J. A., Martins, A. P., Costa, F. A. d., \& Benrimoj, S. I. (2010). Community pharmacists' and physicians' inter-professional work: Insights from qualitative studies with multiple stakeholders. Revista Portuguesa de Clínica Geral, 26(6), 590-606. https://doi.org/10.32385/rpmgf.v26i6.10802

Rathbone, A. P., Mansoor, S. M., Krass, I., Hamrosi, K., \& Aslani, P. (2016). Qualitative study to conceptualise a model of interprofessional collaboration between pharmacists and general practitioners to support patients' adherence to medication. BMJ Open, 6(3). https://doi.org/10.1136/bmjopen-2015-010488

Rieck, A. M. (2014). Exploring the nature of power distance on general practitioner and community pharmacist relations in a chronic disease management context. Journal of Interprofessional Care, 28(5), 440-446. https://doi.org/10.3109/13561820.2014.906390

Rosenthal, M., Austin, Z., \& Tsuyuki, R. T. (2010). Are pharmacists the ultimate barrier to pharmacy practice change? Canadian Pharmacists Journal, 143(1), 37-42. https://doi.org/10.3821/1913-701X-143.1.37 
Rubio-Valera, M., Jove, A. M., Hughes, C. M., Guillen-Sola, M., Rovira, M., \& Fernandez, A. (2012). Factors affecting collaboration between general practitioners and community pharmacists: A qualitative study. BMC Health Services Research, 12.

https://doi.org/10.1186/1472-6963-12-188

Snyder, M. E., Zillich, A. J., Primack, B. A., Rice, K. R., McGivney, M. A. S., Pringle, J. L., \& Smith, R. B. (2010). Exploring successful community pharmacist-physician collaborative working relationships using mixed methods. Research in Social and Administrative Pharmacy, 6(4), 307-323. https://doi.org/10.1016/j.sapharm.2009.11.008

Svensberg, K., Kälvemark Sporrong, S., Håkonsen, H., \& Toverud, E.-L. (2015). 'Because of the circumstances, we cannot develop our role': Norwegian community pharmacists' perceived responsibility in role development. International Journal of Pharmacy Practice, 23(4), 256-265. https://doi.org/10.1111/ijpp.12154

Tan, S. \& Moghaddam, F. M. (1999). Positioning in intergroup relations. In R. Harré \& L. van Langenhove (Eds.), Positioning theory: Moral contexts of intentional action (pp. 178194). Oxford: Blackwell.

Traulsen, J. M., \& Bissel P. (2004). (9) Theories of professions and the pharmacist. International Journal of Pharmacy Practice, 12(2), 107-14. https://doi.org/10.1211/0022357023727

Van, C., Mitchell, B., \& Krass, I. (2011). General practitioner-pharmacist interactions in professional pharmacy services. Journal of interprofessional care, 25(5), 366-372. https://doi.org/10.3109/13561820.2011.585725

Walsh, D., \& Downe, S. (2005). Meta-synthesis method for qualitative research: A literature review. Journal of Advanced Nursing, 50(2), 204-211. https://doi.org/10.1111/j.13652648.2005.03380.x

Weissenborn, M., Haefeli, W. E., Peters-Klimm, F., \& Seidling, H. M. (2017). Interprofessional communication between community pharmacists and general practitioners: $A$ qualitative study. International Journal of Clinical Pharmacy, 39(3), 495-506. https://doi.org/10.1007/s11096-017-0450-6

World Health Organization. (1998). Joint statement by the International Pharmaceutical Federation and World Medical Association. Working relationship between physicians and pharmacists in medicinal therapy. Retrieved from http://iris.wpro.who.int/bitstream/handle/10665.1/7308/WPR RC049 Statement FIP W MA 1998 en.pdf

World Health Organization. (2010). Framework for action on interprofessional education \& collaborative practice. Retrieved from http://apps.who.int/iris/bitstream/handle/10665/70185/WHO HRH HPN 10.3 eng.pdf?s equence $=$

World Health Organization. (2016). Medication errors: Technical series on safer primary care. Retrieved from http://apps.who.int/iris/bitstream/handle/10665/252274/9789241511643eng.pdf;jsessionid=914525E461F00F3C3F6462E09F8E58F9?sequence $=1$ 
Positioning Each Other

World Health Organization. (2017). Medication without harm - Global patient safety challenge on medication safety. Retrieved from http://apps.who.int/iris/bitstream/handle/10665/255263/WHO-HIS-SDS-2017.6eng.pdf?sequence $=1$

Zillich, A. J., McDonough, R. P., Carter, B. L., \& Doucette, W. R. (2004). Influential characteristics of physician/pharmacist collaborative relationships. Annals of Pharmacotherapy, 38(5), 764-770. https://doi.org/10.1345/aph.1D419 


\section{Appendix 1}

Search strategies in electronic databases

Database: Embase (Ovid) <1974 to 2016 Dec 05>

Searched 6. Dec.2016

1 pharmacy/ (73968)

2 pharmacist/ (65541)

3 (pharmacist* or pharmacy or pharmacies or drug store*).ti,ab,kw. (104064)

41 or 2 or $3(143294)$

5 general practitioner/ (89958)

6 exp primary health care/ (148865)

7 general practice/ (81848)

8 private practice/ (16044)

9 (((family or general or primary care or private) adj2 (doctor* or physician* or practitioner* or practice)) or GP*).ti,ab,kw. (325261)

105 or 6 or 7 or 8 or $9(490616)$

11 trust/ (10443)

12 (trust* or mistrust* or distrust* or reliance).ti,ab,kw. (72015)

1311 or $12(75712)$

144 and 10 and $13(465)$

Comment from librarian: Primary medical care is secondary to primary health care

Epub Ahead of Print, In-Process \& Other Non-Indexed Citations, Ovid MEDLINE(R) Daily and Ovid MEDLINE(R) $<1946$ to Present $>$

Searched 6. Dec.2016

1 Pharmacy/ (12998)

2 Pharmacists/ (13735)

3 (pharmacist* or pharmacy or pharmacies or drug store*).ti,ab,kw. (55978) 
Positioning Each Other

41 or 2 or $3(66260)$

5 general practitioners/ or physicians, family/ or physicians, primary care/ (24250)

6 Primary Health Care/ (69460)

7 exp General Practice/ (73996)

8 Private Practice/ (8202)

9 (((family or general or primary care or private) adj2 (doctor* or physician* or practitioner* or practice)) or GP*).ti,ab,kw. (280705)

105 or 6 or 7 or 8 or $9(371065)$

11 Trust/ (8009)

12 (trust* or mistrust* or distrust* or reliance).ti,ab,kw. (58449)

1311 or $12(61708)$

144 and 10 and $13(114)$

Comment from librarian: Family practice is secondary to General practice.

Database: PsycINFO (Ovid) <1806 to Nov Week 4 2016>

Searched 6. Dec.2016

1 pharmacy/ or pharmacists/ (1665)

2 (pharmacist* or pharmacy or pharmacies or drug store*).tw. (5376)

31 or $2(5398)$

4 general practitioners/ or family medicine/ or family physicians/ (7719)

5 primary health care/ (15069)

6 private practice/ (1296)

7 (((family or general or primary care or private) adj2 (doctor* or physician* or practitioner* or practice)) or GP*).tw. (39337)

84 or 5 or 6 or $7(51011)$

9 "trust (social behavior)"/ (8163)

10 (trust* or mistrust* or distrust* or reliance).tw. (50268) 
Positioning Each Other

119 or $10(50415)$

123 and 8 and $11(24)$

Comment from librarian: Family medicine is used as a keyword in this database on articles about general practitioners (GPs). This is strange, since GPs is also a keyword.

Svemed+ (Karolinska Institutet)

Searched: 6. Dec. 2016

2 noexp:"Pharmacy" 142

3 noexp:"Pharmacy" AND noexp:"pharmacists"

4 pharmacist* OR pharmacy OR pharmacies OR "drug store*" OR farmas $\varnothing \mathrm{yt}$ * OR farmaceut* OR apotek* 2685

$5 \quad \# 2$ OR \#3 OR \#4 2685

8 noexp:"General Practitioners" $\quad 230$

10 noexp:"Physicians, Primary Care" 8

11 noexp:"Physicians, Family" 1286

12 noexp:"primary health care" 2001

13 exp:"General Practice" 3167

14 noexp:"Private Practice" 256

15 ((family OR general OR primary care OR private) AND (doctor* OR physician* OR practitioner* OR practice)) OR GP* 5304

16 allmennlege* OR allmännläkar* OR "praktiserende læge*" OR fastlege* 279

17 \#8 OR \#10 OR \#11 OR \#12 OR \#13 OR \#14 OR \#15 OR \#16 6640

18 exp:"trust" 128

19 trust* OR mistrust* OR distrust* OR reliance OR tillit* OR "stole på" OR förtroende OR tillid $\quad 260$

$20 \quad \# 18$ OR \#19 260

$21 \quad \# 5$ AND \#17 AND \#20 1 
Positioning Each Other

Web of Science (Thomson \& Reuters)

Indexes=SCI-EXPANDED, SSCl, A\&HCI Timespan=All years

Searched: 6. Dec. 2016

\# 1 46,370 TOPIC: (pharmacist* or pharmacy or pharmacies or "drug store*")

\# 2 147,776 TOPIC: (((family or general or "primary care" or private) NEAR/2 (doctor* or physician* or practitioner* or practice)) or GP)

\# $3 \quad 97,927$ TOPIC: (trust* or mistrust* or distrust* or reliance)

\# $4 \quad 87$ : \#3 AND \#2 AND \#1 
Positioning Each Other

\section{Appendix 2}

Figure describing the analysis process from preliminary thematic categories to final results
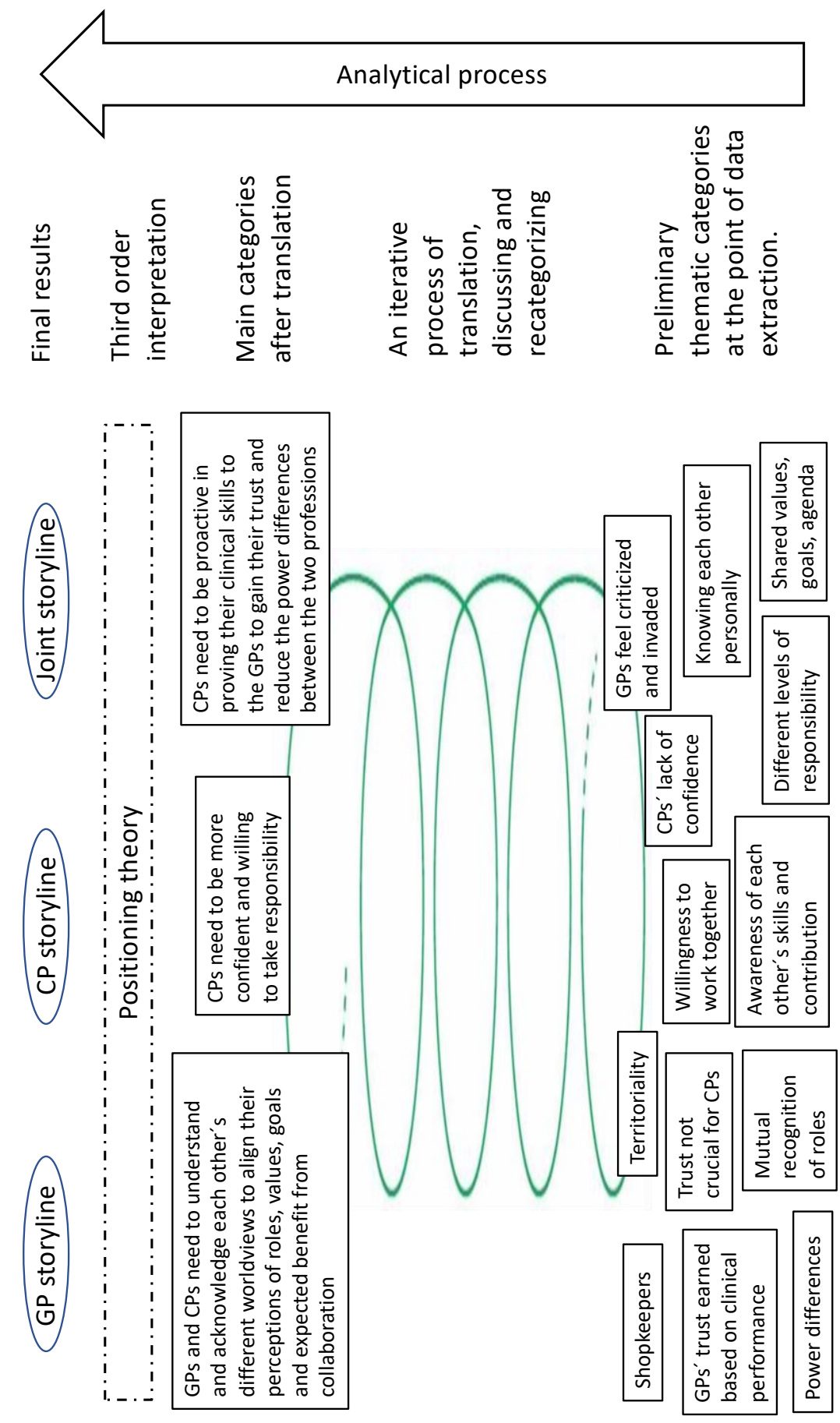


\section{Appendix 3}

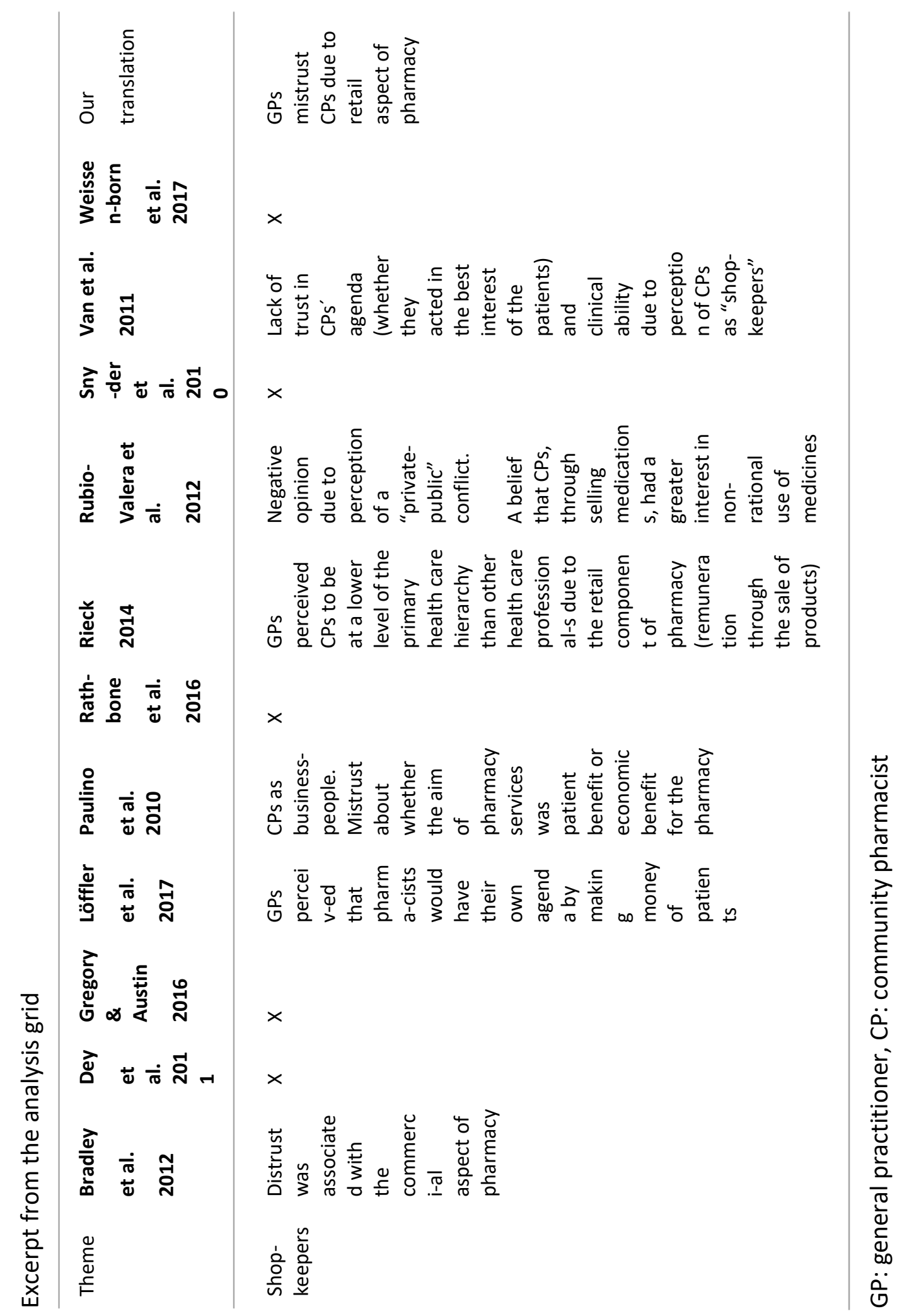


${ }^{1}$ We use the terms "CP" and "GP" in this article to refer to community pharmacists and physicians working in primary care, although the terms used in the primary articles upon which this metasynthesis is based varies (e.g. pharmacists, family physicians, physicians). One of the primary articles includes a mix of general practitioners and hospital physicians, but for pragmatic reasons we chose to use the term GP throughout our article since the vast majority of physicians included in the primary studies were general practitioners.

${ }^{2}$ Defined by Atkins et al. (2008) as: "the comparison of themes across papers and an attempt to "match" themes from one paper with themes from another, ensuring that a key theme captures similar themes from different papers". 